Correction

\title{
Correction to: Impact Performance of Modern Football Helmets
}

\author{
David C. Viano, ${ }^{1}$ Chris Withnall, ${ }^{2}$ and David Halstead ${ }^{3,4}$
}

${ }^{1}$ ProBiomechanics LLC, 265 Warrington Rd., Bloomfield Hills, MI 48304, USA; ${ }^{2}$ Biokinetics and Associates Ltd., 2470 Don Reid Drive, Ottawa, Ontario K1H 1E1, Canada; ${ }^{3}$ University of Tennessee, College of Engineering, Sports Biomechanics Impact Research Lab, 416 East Stadium Hall, Knoxville, TN 37996, USA; and ${ }^{4}$ Southern Impact Research Center, LLC, 304 Dunavant Drive, Rockford, TN 37853, USA

\section{Correction to: ANNALS BIOMEDICAL ENGINEERING 40(1):160-174 \\ DOI 10.1007/S10439-011-0384-4}

This erratum is to correct headings listing the impact location and speed in Figs. 5 and 6. The following provides corrected Figs. 5 and 6. The data is unchanged. The authors apologize for any inconvenience this might have caused.

Address correspondence to David C. Viano, ProBiomechanics LLC, 265 Warrington Rd., Bloomfield Hills, MI 48304, USA. Electronic mail: dviano@comcast.net

The online version of the original article can be found under doi: 10.1007/s10439-011-0384-4. 


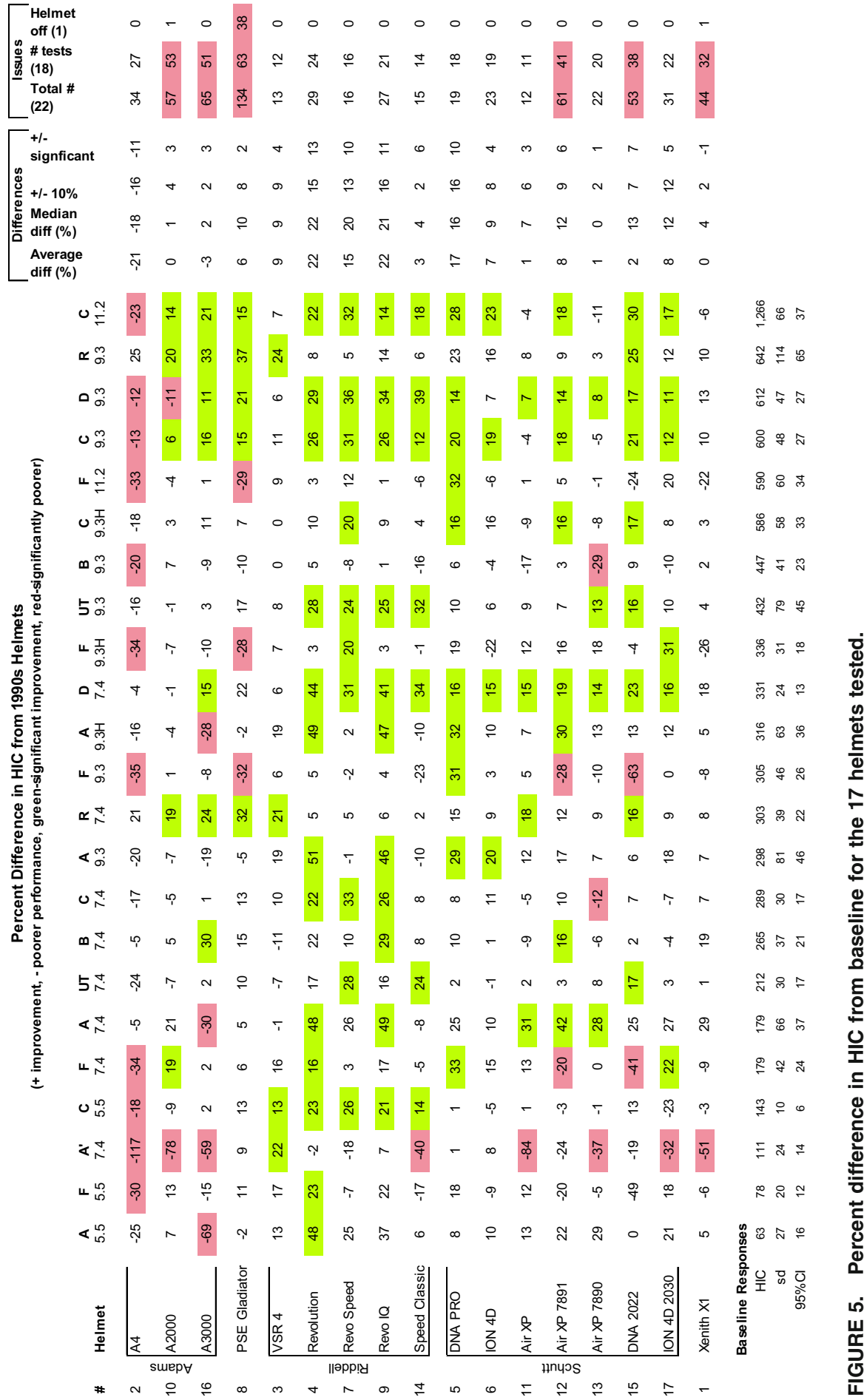




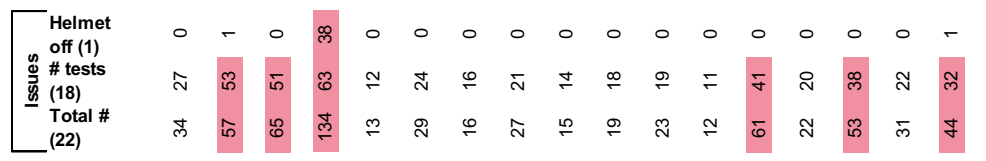

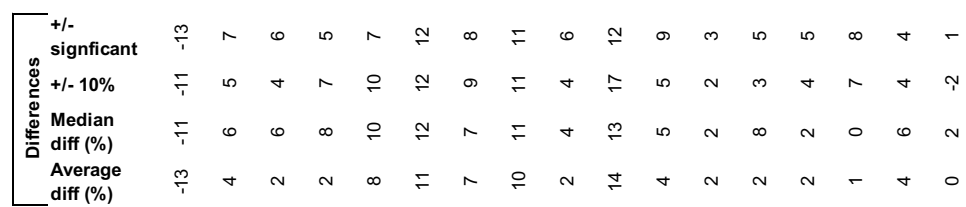

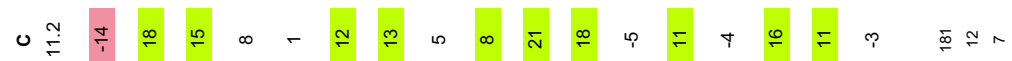

○

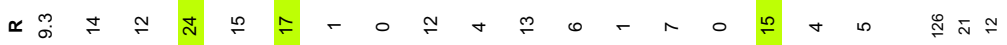

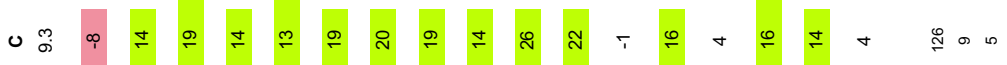

=

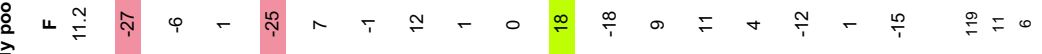

䆣

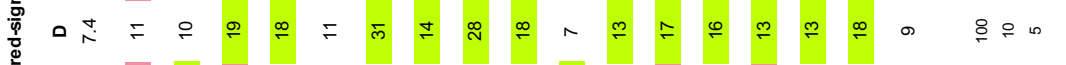

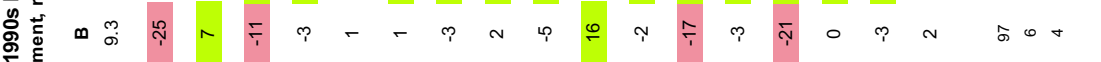

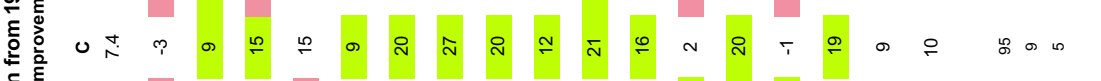

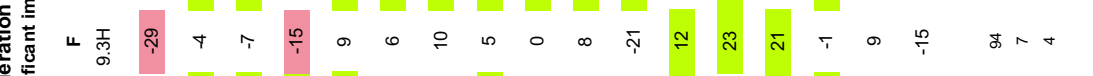

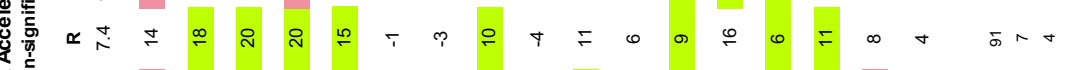

需离

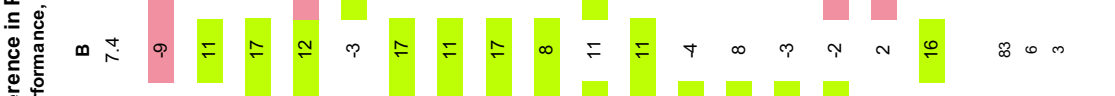

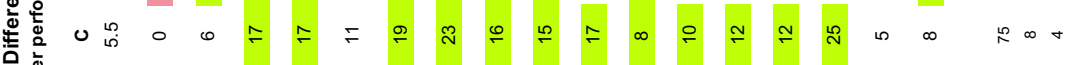

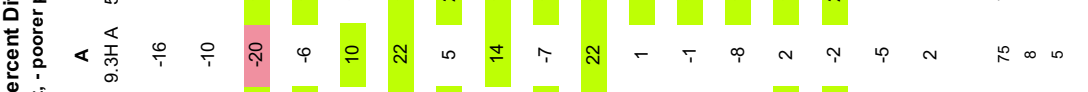

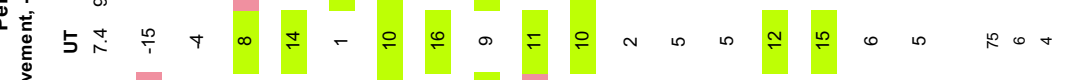

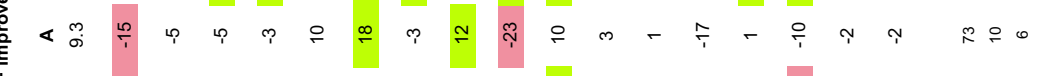

少

通

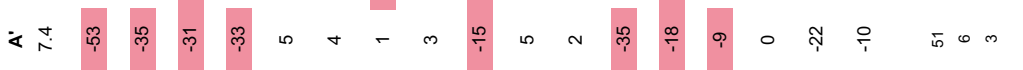

ᄂ 吕

《员

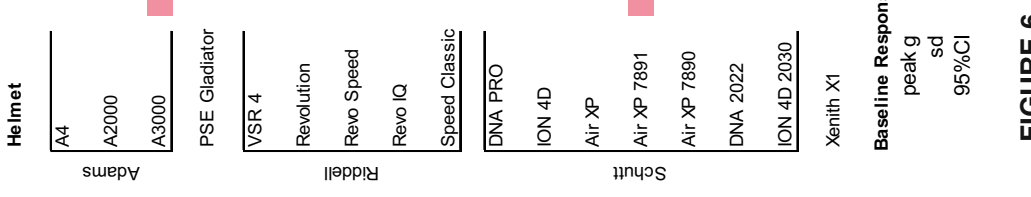

